\title{
Life cycle assessment of lignocellulosic biomass pretreatment methods in biofuel production
}

\author{
Aashish Prasad $^{1} \cdot$ Maria Sotenko $^{1} \cdot$ Thomas Blenkinsopp $^{1} \cdot$ Stuart R. Coles $^{1}$ (I)
}

Received: 15 August 2014 / Accepted: 19 October 2015 / Published online: 9 November 2015

(C) The Author(s) 2015. This article is published with open access at Springerlink.com

\begin{abstract}
Purpose In converting lignocellulosic biomass into biofuel, a pretreatment stage is required in order to make the biomass more readily available for the transformation. There are numerous pretreatment techniques that can be chosen, which are broken down into four categories: chemical, physical, physicochemical, and biological. The aim of this work is to provide a new assessment for some of the emerging technologies using life cycle assessment (LCA) combined with an analysis of the overall product yield.

Methods Using literature data, an LCA of four different pretreatment methods was carried out. Liquid hot water (LHW), steam explosion (SE), dilute acid (DA), and organosolv (OS) were chosen as the most common techniques with high scalability potential. Models were constructed using GaBi software. A cradle-to-gate analysis was selected with a common model of the corn stover growth and harvesting cycle being combined with the individual models for each pretreatment. Four impact categories were analyzed, and a selection has been discussed based on relevance to the biofuel production process.

Results and discussion In nearly all of the impact categories, DA performs the worst due to the length of the process $(12 \mathrm{~h})$ and the amount of electricity required to elevate the
\end{abstract}

Responsible editor: Peter Saling

Electronic supplementary material The online version of this article (doi:10.1007/s11367-015-0985-5) contains supplementary material, which is available to authorized users.

Stuart R. Coles

stuart.coles@warwick.ac.uk

1 WMG, University of Warwick, Gibbet Hill Road, Coventry CV4 7AL, UK temperature to $60^{\circ} \mathrm{C}$ for that time period. In many of the other categories, the remaining three pretreatments perform comparably to each other with the exception of LHW which has significantly reduced $\mathrm{CO}_{2}$ emissions. LHW has slightly higher water depletion rates than both SE and OS, which is to be expected given the nature of the process. In terms of product yield, LHW produced twice as much total sugar than any of the other processes.

Conclusions The project concluded that while LHW and SE are viable options for the pretreatment of biomass, LHW is the most suitable technique for the pretreatment of corn stover. This pretreatment was environmentally friendly as it produced the lowest $\mathrm{CO}_{2}$ emissions, aligning with the main objective behind developing biofuels from agricultural residues. The process was also technically the most effective as it resulted in the highest sugar yields.

Keywords Biofuel · Biomass · Dilute acid · Life cycle assessment $\cdot$ Lignocellulose $\cdot$ Liquid hot water · Organosolv · Steam explosion

\section{Introduction}

Social responsibility coupled with concerns about carbon emissions and fossil fuel supplies have led researchers to investigate alternative sources of energy. The US Energy Information Administration (EIA) has established that fossil fuels currently supply nearly $80 \%$ of the world energy use and are projecting the global energy consumption to increase by $56 \%$ by 2040 owing to an increase in the world population and global industrialization (Energy Information Administration 2013). This massive escalation in the demand for energy coupled with ever increasing depletion rates of fossil fuel reserves and the desire to reduce greenhouse gas emissions have 
converged into an urgent need for sustainable energy systems based on renewable resources.

First generation biofuels derived predominantly from plant matter such as grains, sugar beet, and oil seeds do not present a sustainable option as a substitute to fossil fuel production mainly because the majority of them are being shown to provide little or no net life cycle benefit in terms of carbon dioxide and other greenhouse gas (GHG) emission reductions, especially when land use changes are taken into account (Eisentraut 2010) (Timilsina and Shrestha 2010).

Second generation or advanced biofuels are produced from the nonedible sources and residues of crops as well as waste biomass. The conversion of abundant lignocellulosic biomass to second generation biofuels as transportation fuels presents a practical option for improving long-term energy security, reducing greenhouse gas emissions, and mitigating waste sources. It has been reported that cellulosic ethanol has the potential to reduce greenhouse gas emissions of a vehicle by $86 \%$ (Wang et al. 2007), whereas first generation biofuels only reduce the emissions by approximately $12-13 \%$ (Stephen et al. 2013) when compared with conventional petrol.

Lignocellulosic materials such as agricultural residues (e.g., wheat straw, sugarcane bagasse, and corn stover), forest residues (hardwood and softwood), herbaceous and woody energy crops, as well as dedicated crops (switch grass, Salix) are abundantly available and are considered to be attractive renewable sources of energy. Using residues for biofuel production provides the biggest advantage because it reduces the competition for land as they mitigate the use of crop-origin materials and prevent biomass from ending up in landfill.

Approximately $90 \%$ of the dry weight of most plant materials is stored in the form of cellulose, hemicellulose, lignin, and pectin. The general composition of lignocellulosic biomass is illustrated in Table 1 (Limayem and Ricke 2012). The structural and chemical composition is highly variable between different feedstocks influenced by genetic and environmental factors.

Cellulose, a polymer of D-glucose and the main substrate for fermentation to bioethanol, provides the structural support for plants; hemicellulose plays a binding role, whereas lignin ensures robustness, chemical and biological resistance. Prior to hydrolysis of cellulose and conversion of sugars to ethanol, the biomass has to be pretreated. The main aim of the

Table 1 General composition of lignocellulosic biomass

\begin{tabular}{ll}
\hline Biomass component & Percentage \\
\hline Lignin & $\sim 15 \%$ \\
Cellulose & $35-50 \%$ \\
Hemicellulose & $20-35 \%$ \\
Others including ash, pectin, etc. & $\sim 15 \%$ \\
\hline
\end{tabular}

pretreatment stage is to remove the protective layer of lignin from the biomass in order to make the sugars more accessible for hydrolysis. Pretreatment is one of the most expensive processing steps within the conversion of lignocellulosic biomass to fermentable sugars. However, with the advancement of novel pretreatment technologies, there is great potential in the improvement of efficiency and reduction of costs in the production of second generation biofuels. The area of biomass pretreatment has been reviewed by Agbor et al. and more comprehensive technical detail on the pretreatment can be found there (Agbor et al. 2011).

The major performance goals for pretreatment technologies, according to the International Energy Agency (IEA), is highlighted below (Sims and Taylor 2008).

- Improve hexose and pentose sugar yields in downstream processing.

- Facilitate the recovery of lignin for later combustion.

- Reduce the formation of by-products (e.g., furfural and hydroxymethyl furfurals) that inhibit downstream hydrolysis or fermentation processes.

- Be flexible enough to pretreat varying lignocellulosic feedstock.

- Avoid expensive size reduction techniques.

- Employ inexpensive chemicals and reduce waste formation.

- Have low energy requirements and low capital costs.

The pretreatment techniques can be categorized into four groups according to their methodology, as illustrated in Table 2.

It is clear that there is a wide range of pretreatments available when looking to convert lignocellulosic biomass into biofuel. Most of the developed and reviewed methods are

Table 2 Pretreatment methodologies

\begin{tabular}{ll}
\hline Pretreatment Group & Methodology \\
\hline Physical & Wet milling \\
& Dry milling \\
& Grinding \\
& Microwave \\
& Microwave/ionic liquid \\
Physicochemical & Steam explosion \\
& Catalyzed SE \\
& Ammonia fiber explosion \\
& Liquid hot water \\
Chemical & Alkaline hydrolysis \\
& Acid pretreatment \\
& Organosolv \\
Biological & Ozonolysis \\
\hline
\end{tabular}


based on lab scale experiments, whereas just a few techniques have been shown to be scalable. In general, many of these processes have not been developed to the large scale production required to meet the demands of replacing oilbased fuels with renewable energy sources. With most of the pretreatment methods still being under development, there is a scarce knowledge on their environmental impacts in general and $\mathrm{CO}_{2}$ emissions in particular techniques. This paper aims to establish which of the scalable processes are most suitable for the biofuel production. The yield of the process has been incorporated into the overall life cycle assessment (LCA) model to allow for a fair comparison in terms of biofuel produced.

\section{Life cycle assessment}

\subsection{Goal and scope}

Having assessed the current literature on the various methods, the next stage was to perform an analytical comparison of the techniques that are most common and widespread. The techniques that were chosen to be further analyzed with a life cycle assessment were as follows.

- Liquid hot water-a method in which biomass gets cooked in liquid water at extremely high temperatures. The water is maintained at its liquid state due to a huge increase in pressure.

- Organosolv - use of an organic solvent or combination of organic solvents and water, with or without a catalyst, in order to remove lignin before enzymatic hydrolysis of the cellulose fraction.

- Dilute acid - this technique aims to solubilize hemicellulose completely while keeping most of the cellulose and lignin intact so that the enzymatic digestibility of cellulose is improved.

- Steam explosion - saturated steam at high pressure is added to initiate hydrolysis. The pressure is then suddenly reduced, exposing the biomass to an explosive decompression which opens the biomass structure and thereafter improving the enzyme accessibility.

These techniques were found to have the greatest potential to be applied on industrial scale in the process of bioethanol production from lignocellulosic feedstocks based on yield and scalability. The LCA was performed by simulating the different pretreatment processes with the help of the GaBi software package.

In order to analyze the proposed pretreatment methods, it is first crucial to choose a lignocellulosic feedstock to be able to fairly compare the four pretreatment methods based on available data. For the purpose of this study, the feedstock that has been chosen is corn stover.
The system boundary for this life cycle assessment is from cradle-to-gate. This includes the burden of all input processes for the corn growth and harvesting processes. While the goal was to study the effect of the pretreatment method, an initial model that included all the inputs and energy consumption for the growth and harvesting process of corn stover and was created as the information did not exist in the database.

In total, there were five models that were developed (see Electronic Supplementary Material for more details). In addition to the growth model, a model was made for each of the four pretreatment methods, with the input of corn stover to these models being the output from the growth model.

This study will focus on corn production from typical corn farming locations that are on the Corn Belt. This study focuses on the county level corn production, and eight different counties from seven different states are selected.

\subsection{Life cycle inventory}

Data for the corn growth and harvesting processes have been adapted from a previous study conducted by Kim et al. (2009). They have obtained their data for corn yield from a 4-year average from 2000 through 2003 adapted from the National Agricultural Statistics Service (NASS), which is available to the public domain (Dougherty 2008). Additionally, state-level agronomic inputs (fertilizers and agrochemicals) and fuel consumption data from the NASS as well as the Economic Research Service, respectively (McBride 2005).

This study also made use of published journal articles and research papers in order to obtain data for the pretreatment conditions, inputs, equipment used, and outputs. Table 3 helps provide information about the kind of data and the source from where it was acquired. The experimental conditions for the four pretreatment methods are explained in Table 4. The experimental conditions chosen for this study were found to be the optimal conditions for the pretreatment of corn stover based on literature research.

The harvesting process for corn kernels leaves behind cobs, leaves, including stalks, and husks on the farm field as residue. These residues are collectively known as corn stover and represent the above-ground, nongrain part of the plant that is usually left on the field. These abundantly found lignocellulosic wastes can be converted into biofuel in order to maximize their use.

A recent publication by the Iowa Corn Promotion Board (ICPB) stated that Iowa produced 2.4 billion bushels (approx. 84.5 billion liters) of corn in 2011, which correlated to approximately 67 million dry tons of corn stover production. This was estimated after assuming a realistic $50 \%$ harvesting index (1:1 corn grain to corn stover ratio dry basis). In addition to this, approx. $50 \%$ of the stover has to be left on the field in order to prevent soil erosion and maintain the required level of 
Table 3 Data sources

\begin{tabular}{|c|c|c|}
\hline Process & Data source & Type of data \\
\hline Corn growth & $\begin{array}{l}\text { - Kim et al. (2009) } \\
\text { - Dougherty (2008) } \\
\text { - McBride (2005) }\end{array}$ & $\begin{array}{l}\text { Nitrogen, phosphate and potassium fertilizer, herbicide, insecticide, lime, diesel, } \\
\text { gasoline, LPG, and electricity consumption during growth and harvesting }\end{array}$ \\
\hline Water & • Pohly (2014) & Water consumption during corn growth for one acre field \\
\hline Corn harvesting & $\begin{array}{l}\text { - Kim et al. (2009) } \\
\text { - Dougherty (2008) }\end{array}$ & Corn yield, corn production from eight counties on the US Corn Belt \\
\hline Corn stover milling energy & - Bitra et al. (2009) & Optimum total specific energy required for milling corn stover \\
\hline SE pretreatment & - Varga et al. (2004) & Experimental inputs, outputs, and energy consumptions \\
\hline $\mathrm{DA}(\mathrm{HCl})$ pretreatment & - Zu et al. (2014) & Experimental inputs, outputs, and energy consumptions \\
\hline LHW pretreatment & • Mosier et al. (2005) & Experimental inputs, outputs, and energy consumptions \\
\hline OS pretreatment & $\begin{array}{l}\text { - Cybulska et al. (2012) } \\
\text { - Barajas-Solano et al. (2014) }\end{array}$ & Experimental inputs, outputs, and energy consumptions \\
\hline
\end{tabular}

$L H W$ liquid hot water, $S E$ steam explosion, $D A$ dilute acid, $O S$ organosolv

soil fertility. Keeping this in mind, the ICPB have estimated that more than 75 million dry tons of corn stover can be sustainably harvested in the USA (Ertl 2013).

The three main components of corn stover are cellulose ( $\sim 38 \%)$, hemicellulose ( $\sim 26 \%)$, and lignin $(\sim 19 \%)$ and can slightly vary according to time of growth and growing conditions (Pordesimo et al. 2005). Corn stover presents to be a suitable feedstock for the production of ethanol because of its low cost, abundance, and proximity to current grain-toethanol conversion facilities in the USA.

\subsection{Life cycle impact analysis}

As this study is focusing on the impact of pretreatment (and as a consequence, feedstock growth), impact categories that are important to agriculture and manufacturing were selected. These include climate change (via $\mathrm{CO}_{2}$ emissions), water consumption, terrestrial, and aquatic eutrophication, and acidification were analyzed.

\subsection{Assumptions}

A harvesting index of $50 \%$ was considered. This is a reasonable assumption to make because the weight of the aboveground part of the corn plant is attributed as $46 \%$ grain and
$54 \%$ stover (Pordesimo et al. 2005). Therefore, for every kiligram of corn grain produced, approximately $1 \mathrm{~kg}$ of corn stover will also be produced. Hence, the corn yield data obtained from Kim et al. (2009) for the eight counties can directly be used as data for corn stover yield.

It was also assumed that $50 \%$ of the corn stover produced was left on the field. This was the required level in order to prevent soil erosion and allow the soil to maintain the necessary level of nutrients. Experts have identified that $50 \%$ of corn stover removal rates are within the tolerance limits (Gallagher et al. 2003).

The data in the LCA study for water consumption was based upon a 100-day growing period for a 1-acre field (Barr et al. 2012) (Pohly 2014). This study also assumes that the corn stover used in all the experiments were identical in composition, size (after milling), and all other aspects. This is a justified assumption to make even though slight variations could exist as it would not have a huge hindrance when overall energy consumptions are taken into consideration.

The corn stover was assumed to be air dried in the field. Two of the experiments also did not provide information about the type of boilers and reactors used during the experiment, and hence, similar experiments were analyzed in order to understand the power rating and type of equipment usually employed for the experiment.

Table 4 Experimental conditions for pretreatment of corn stover

\begin{tabular}{|c|c|c|c|c|c|c|}
\hline Reference & Pretreatment & Temp $\left({ }^{\circ} \mathrm{C}\right)$ & Time (min) & Mass used (g) & Conditions & Yield \\
\hline Varga et al. (2004) & SE & 190 & 5 & 180 & $2 \mathrm{wt} \% \mathrm{H}_{2} \mathrm{SO}_{4}$ & $73 \%$ \\
\hline Zu et al. (2014) & DA & 120 & 40 & 10 & $1.1 \mathrm{wt} \%$ aq. $\mathrm{HCl} 2$. Lime $(10 \mathrm{wt} \%) 60^{\circ} \mathrm{C}, 12 \mathrm{~h}$ & $70 \%$ \\
\hline Mosier et al. (2005) & LHW & 190 & 20 & 5.2 & $28.6 \mathrm{~cm}^{3} \mathrm{H}_{2} \mathrm{O}$ (deionized) & $80 \%$ \\
\hline $\begin{array}{l}\text { Cybulska et al. (2012) } \\
\text { Barajas-Solano et al. (2014) }\end{array}$ & OS & 140 & 20 & 10 & $\begin{array}{l}\text { EtOAc: } \mathrm{EtOH}: \mathrm{H}_{2} \mathrm{O} 36.99: 26.31: 37.70 \\
\quad(\text { all } \mathrm{wt} \%)+\mathrm{H}_{2} \mathrm{SO}_{4} 0.49 \mathrm{wt} \%\end{array}$ & $70 \%$ \\
\hline
\end{tabular}

$L H W$ liquid hot water, $S E$ steam explosion, $D A$ dilute acid, $O S$ organosolv 
The system boundary for the LCA study was set to be after the pretreatment process was completed and before the sugars were fermented to produce bioethanol. Therefore, when analyzing and comparing the final product quality in terms of sugar yields for the different methods of pretreatment, it is necessary to make the assumption that the processes for enzymatic hydrolysis and fermentation would be identically performed on each of the fermentable sugars produced.

The data that was used during the LCA simulations were from lab-scale experiments. These pretreatment processes have not yet been employed in industrial processes, and hence, data could not be obtained for industrial applications. GaBi simulates the inputs and outputs in all models to be evenly scaled up for larger quantities, including energy consumptions. In reality, this might not be the case as a $100-\mathrm{L}$ reactor may not necessarily consume 100 times the energy consumed by a $1-\mathrm{L}$ reactor. The analysis also does not include the effects of transportation as it is assumed that transportation would be the same for all processes and is therefore not a discriminator between them.

\section{Life cycle interpretation}

The milled corn stover produced from the corn stover growth and harvesting model formed the input for the four pretreatment methods chosen to be analyzed. Simulations were run based on a fixed output of $1 \mathrm{~kg}$ of fermentable sugar. Therefore, the energy inputs and environmental impacts of the four pretreatment techniques were analyzed for producing $1 \mathrm{~kg}$ of fermentable sugar. As can be seen below, there are significant differences between each of the four pretreatment methodologies even though the environmental burden has been included in this analysis. This presents a "worst-case" scenario based on the assumption that the corn was utilized for food consumption but still highlights the large variance between treatments.

\subsection{Climate change}

The amount of $\mathrm{CO}_{2}$ emitted from the four pretreatment techniques was analyzed and is detailed in Table 5. It is clear from the data that the $\mathrm{CO}_{2}$ emissions from DA pretreatment dwarf

Table $5 \quad \mathrm{CO}_{2}$ emissions

\begin{tabular}{lc}
\hline Pretreatment & $\mathrm{CO}_{2}$ emissions $(\mathrm{kg}) \mathrm{CO}_{2}$ equivalent \\
\hline $\mathrm{SE}$ & 14.30 \\
$\mathrm{DA}$ & 385.00 \\
LHW & 0.94 \\
OS & 9.23 \\
\hline
\end{tabular}

$L H W$ liquid hot water, $S E$ steam explosion, $D A$ dilute acid, $O S$ organosolv those from the other processes. Liquid hot water (LHW) has the smallest impact, approximately 15 times smaller than steam explosion (SE). In order to understand the reasons for such a massive difference between $\mathrm{CO}_{2}$ emissions for dilute acid (DA) pretreatment and the other techniques, it is important to understand which of the processes within the DA pretreatment contribute to the overall $\mathrm{CO}_{2}$ emitted.

Of the total of $385 \mathrm{~kg}$ of $\mathrm{CO}_{2}$ produced, the production of electricity for the DA stage produced $54.6 \mathrm{~kg}$ of $\mathrm{CO}_{2}$ with the production of electricity for the lime treatment (which alters the lignin structure and swells the cellulose surface) step accounting for $327 \mathrm{~kg}$ of $\mathrm{CO}_{2}, 85 \%$ of the overall emissions. This is due to the process employing a water bath that was maintained at $60{ }^{\circ} \mathrm{C}$ for $12 \mathrm{~h}$. This operation time, combined with the elevated temperature, was far in excess of the other treatments and as such, highlights the reason for the large disparity.

A common feature in either using SE or DA was that the electricity contributed the most toward the overall $\mathrm{CO}_{2}$ emissions ( 88 and $99 \%$, respectively). This shows that efforts has to be made in order to reduce the $\mathrm{CO}_{2}$ emitted by shifting to greener and renewable energy sources when looking to make biofuels as the end product. In these two cases, it is difficult to avoid the energy requirements due to the high working temperatures however, by utilizing a combination of renewable energy sources (solar, hydro, or wind power) should lead to decreased $\mathrm{CO}_{2}$ emissions by a reduction in fossil fuel usage.

\subsection{Eutrophication}

Eutrophication is caused by the addition of anthropogenic inputs to the Earth's surface and the atmosphere such as nitrogen and phosphorus. This nutrition enrichment or eutrophication can cause highly undesirable changes to the ecosystem's structure and function (Smith et al. 1999). Table 6 shows the data for both the terrestrial and aquatic eutrophication potential of the four pretreatment techniques.

On analyzing the contribution of each process to the final amount of nitrogen and phosphorus for all four pretreatment techniques, it was seen that the corn growth and harvesting process had the majority of contribution. This is logical because of the amount of nitrogen, phosphorus, and potassium fertilizers that are added to the farmlands in order to enrich the

Table 6 Eutrophication potentials

\begin{tabular}{lll}
\hline Pretreatment & $\begin{array}{l}\text { Terrestrial eutrophication } \\
\text { (moles } \mathrm{N}_{2} \text { equiv.) }\end{array}$ & $\begin{array}{l}\text { Aquatic eutrophication } \\
\text { (kg P equiv.) }\end{array}$ \\
\hline SE & 0.07 & 0.047 \\
DA & 1.80 & 0.029 \\
LHW & 0.25 & 0.026 \\
OS & 0.06 & 0.053 \\
\hline
\end{tabular}

$L H W$ liquid hot water, $S E$ steam explosion, $D A$ dilute acid, $O S$ organosolv 
soil and obtain an increase in the agricultural yield. A certain critical soil phosphorus and nitrogen level is necessary for economic crop production, but above this level, it contributes to algae causing dead zones which threaten important fisheries (National Oceanic and Atmospheric Administration 2014).

According to the United States Department of Agriculture, corn is the main culprit to eutrophication because of the inputs per kilograms of crop. This is shown by the fact that although it is planted on $23 \%$ of the US crop land, it receives $40 \%$ of the fertilizers (Union of Concerned Scientists 2011). Since corn is a highly seasonal crop and for more than half the year no crops grow on the farmland, the addition of a winter crop can provide fertilizer uptake all year round and help reduce eutrophication. Sustainable agriculture requires fertilization strategies that give profitable production but minimize adverse environmental effects. Alternatives include the recycling of animal manures (as opposed to the use of chemical fertilizers) or lying fallow with clover for nitrogen enrichment.

It is clear that the DA has the greatest additional impact on eutrophication out of the three techniques. LHW also has a relatively significant impact on the eutrophication potential. This could be associated with larger quantities of feedstock required to produce $1 \mathrm{~kg}$ of pretreated corn stover, therefore consuming a greater quantity of chemical fertilizers.

\subsection{Water depletion}

Water is an important natural resource and can be an important factor in deciding environmentally favorable methods to pretreat corn stover, especially when the amount of water consumed during the growth and harvesting of corn is taken into account. Table 7 compares the water depletion levels for the four pretreatment techniques.

It is clear that the DA process consumes the most amount of water with remaining three pretreatments having relatively similar values. Upon analyzing the individual process contributions to the overall water consumption, the corn stover growth and harvesting processes contributed to over $90 \%$ of the overall water consumption in all the pretreatment techniques other than DA pretreatment. Conceptually, the impact of all of these processes is very high, but with the majority of the impact coming from the growth stage, it becomes difficult to avoid.

Table 7 Water depletion

\begin{tabular}{ll}
\hline Pretreatment & Water depletion $(\mathrm{kg})$ \\
\hline SE & 260 \\
DA & 560 \\
LHW & 138 \\
OS & 180 \\
\hline
\end{tabular}

$L H W$ liquid hot water, $S E$ steam explosion, $D A$ dilute acid, $O S$ organosolv
Table 8 Acidification potential

\begin{tabular}{ll}
\hline Pretreatment & Acidification potential $\left(\mathrm{kg} \mathrm{SO}_{2}\right.$ equivalent $)$ \\
\hline $\mathrm{SE}$ & 0.045 \\
$\mathrm{DA}$ & 1.290 \\
LHW & 0.075 \\
OS & 0.025 \\
\hline
\end{tabular}

$L H W$ liquid hot water, $S E$ steam explosion, $D A$ dilute acid, $O S$ organosolv

DA pretreatment has a significantly higher level of water depletion as there is water consumed as part of generating the required amount of electricity for the second stage of that process. In order to make the process energy efficient, it would therefore become important to reduce the process time for lime treatment step. In the study that the data was selected from, this was not considered because the focus of that study was to optimize the end sugar yield ( $\mathrm{Zu}$ et al. 2014). This highlights the dichotomy that exists between energy consumption and final product yield and the difficulty in finding the right balance that produces a product that is sustainable environmentally and economically.

\subsection{Acidification potential}

Acidic gases such as sulfur dioxide $\left(\mathrm{SO}_{2}\right)$ react with water in the atmosphere to form "acid rain", a process known as acid deposition. When this rain falls, often a considerable distance from the original source of the gas, it causes ecosystem impairment. Table 8 shows the $\mathrm{SO}_{2}$ emissions from the four pretreatment methods.

The acidification potential also follows the trend of the previous graphs, showing the DA pretreatment to have the biggest impact. A breakdown of the overall $\mathrm{SO}_{2}$ emission showed that the main contributor to this was, again, electricity production for the lime pretreatment step, with a contribution of $86 \%$ to the overall $\mathrm{SO}_{2}$ produced.

LHW had the second highest $\mathrm{SO}_{2}$ emissions out of the four pretreatment methods. The SE pretreatment process produced much lower levels of $\mathrm{SO}_{2}$ in comparison to DA and LHW pretreatment.

In LHW, the corn stover growth and harvesting processes discharged the largest amount of $\mathrm{SO}_{2}$ with $89.3 \%$ of the total $\mathrm{SO}_{2}$ produced from this process. This is most likely due to the heavier usage of fertilizers, herbicides, and insecticides on farmland.

\section{Conclusions}

From the analysis conducted, it can be concluded that a common feature among the impact categories was that the use of electricity was the biggest contributor to the overall 
environmental degradation. This can be mitigated by switching to renewable sources of energy and reducing our reliance on fossil fuels during electricity production. Furthermore, the duration for second stage of DA (12 h) must be shortened in order to make the process efficient and sustainable.

Organosolv (OS) was generally good in all areas of environmental impact with the exception of the $\mathrm{CO}_{2}$ emissions where it produced the second highest amount. This is largely due the production of ethanol as this contributed toward $93.8 \%$ of the total carbon dioxide discharged.

SE was one of the more eco-friendly methods with a particularly low eutrophication and acidification potential, owing to a short residence time of only $2 \mathrm{~min}$. The exception to this was in the $\mathrm{CO}_{2}$ emissions where it was ten times higher than the lowest modeled emissions of LHW.

LHW had very high sugar conversion rates with 90.54 and $81.8 \%$ glucan and xylan conversion rates respectively. The process was environmentally favorable when compared to the other pretreatments because this method employed only pressurized deionized water to pretreat corn stover. This technique produced the lowest $\mathrm{CO}_{2}$ emission which aligns with the main goal behind developing biofuels from agricultural residues.

While LHW might not be the most environmentally friendly in all categories, it performs comparably in every category and had the lowest $\mathrm{CO}_{2}$ emissions by an order of magnitude. It can be concluded that LHW is the most suitable pretreatment technique for the pretreatment of corn stover. The application of this method would improve long-term energy security and develop a greener tomorrow.

Acknowledgments The authors gratefully acknowledge the financial support from the Engineering and Physical Sciences Research Council (EPSRC) - Cleaning Land for Wealth (EP/K026216/1) (MS) and the Innovative Manufacturing Global Research Priority at the University of Warwick.

Open Access This article is distributed under the terms of the Creative Commons Attribution 4.0 International License (http:// creativecommons.org/licenses/by/4.0/), which permits unrestricted use, distribution, and reproduction in any medium, provided you give appropriate credit to the original author(s) and the source, provide a link to the Creative Commons license, and indicate if changes were made.

\section{References}

Agbor VB, Cicek N, Sparling R et al (2011) Biomass pretreatment: fundamentals toward application. Biotechnol Adv 29:675-85
Barajas-Solano AF, Gonzalez-Delgado AD, Kafarov V (2014) Effect of thermal pre-treatment on fermentable sugar production of Chlorella vulgaris. Chem Eng Trans 37:655-660

Barr RL, Mason SC, Navacek MJ et al (2012) Row spacing and seeding rate recommendations for corn in Nebraska. NebGuide

Bitra VSP, Womac AR, Chevanan N et al (2009) Direct mechanical energy measures of hammer mill comminution of switchgrass, wheat straw, and corn stover and analysis of their particle size distributions. Powder Technol 193:32-45

Cybulska I, Brudecki G, Rosentrater K et al (2012) Comparative study of organosolv lignin extracted from prairie cordgrass, switchgrass and corn stover. Bioresour Technol 118:30-36

Dougherty E (2008) USDA report assesses 2008 corn and soybean acreage

Eisentraut A (2010) Sustainable production of second generation biofuels. In: IEA Bioenergy

Ertl D (2013) 2013 Sustainable corn stover harvest. Iowa Corn Promot Board 1-8

Gallagher P, Dikeman M, Fritz J et al (2003) Biomass from crop residues: cost and supply estimates

Kim S, Dale BE, Jenkins R (2009) Life cycle assessment of corn grain and corn stover in the United States. Int J Life Cycle Assess 14:160-174

Limayem A, Ricke SC (2012) Lignocellulosic biomass for bioethanol production: current perspectives, potential issues and future prospects. Prog Energy Combust Sci 38:449-467

McBride W (2005) Commodity cost and returns. In: USDA Econ Res Serv

Mosier N, Hendrickson R, Ho N et al (2005) Optimization of pH controlled liquid hot water pretreatment of corn stover. Bioresour Technol 96:1986-1993

National Oceanic and Atmospheric Administration (2014) "Dead zone" is a more common term for hypoxia, which refers to a reduced level of oxygen in the water. Ocean Facts 1

Pohly J (2014) How much water for corn growth?

Pordesimo LO, Hames BR, Sokhansanj S, Edens WC (2005) Variation in corn stover composition and energy content with crop maturity. Biomass Bioenergy 28:366-374

Sims R, Taylor M (2008) From 1st-to 2nd-generation biofuel technologies. In: IEA Bioenergy http://www.iea.org/publications/ freepublications/publication/2nd_Biofuel_Gen.pdf

Smith V, Tilman G, Nekola J (1999) Eutrophication: impacts of excess nutrient inputs on freshwater, marine, and terrestrial ecosystems. Environ Pollut 100:179-96

Stephen JD, Mabee WE, Saddler JN (2013) Lignocellulosic ethanol production from woody biomass: the impact of facility siting on competitiveness. Energ Policy 59:329-340

Timilsina G, Shrestha A (2010) Biofuels: markets, targets and impacts. http://elibrary.worldbank.org/doi/pdf/10.1596/1813-9450-5364

U.S. Energy Information Administration (2013) EIA projects world energy consumption will increase $56 \%$ by 2040

Union of Concerned Scientists (2011) Corn ethanol's threat to water resources. Energy Water Collis 1-8

Varga E, Réczey K, Zacchi G (2004) Optimization of steam pretreatment of corn stover to enhance enzymatic digestibility. Appl Biochem Biotechnol 113-116:509-523

Wang M, Wu M, Huo H (2007) Life-cycle energy and greenhouse gas emission impacts of different corn ethanol plant types. Environ Res Lett 2:024001. doi:10.1088/1748-9326/2/2/024001

Zu S, Li W, Zhang M et al (2014) Pretreatment of corn stover for sugar production using dilute hydrochloric acid followed by lime. Bioresour Technol 152:364-370 